\title{
АДАПТАЦИЯ БЕЛЫХ МЕДВЕДЕЙ К УСЛОВИЯМ ПАРКА ФЛОРЫ И ФАУНЫ «РОЕВ РУЧЕЙ»
}

\author{
E.O. Nekipelova, I.Yu. Buyanov, \\ M.M. Shushakova, T.N. Tretinnikova
}

\section{THE ADAPTATION OF POLAR BEARS TO THE CONDITIONS OF THE PARK OF FLORA AND FAUNA "ROEV RUCHEY"}

\author{
Некипелова Елена Олеговна - науч. сотр. МАУ \\ «Красноярский парк фрлоры и фауны «Роев ру- \\ чей», г. Красноярск. \\ E-mail: nekipelova73@mail.ru
}

Буянов Иван Юрьевич - канд. с.-х. наук, ст. науч. сотр. МАУ «Красноярский парк фллоры и фрауны «Роев ручей», г. Красноярск.

E-mail: ivyan@mail.ru

Шушакова Маргарита Михайловна - зав. отделом млекопитающих МАУ «Красноярский парк фолоры и фауны «Роев ручей», г. Красноярск. Еmail: ritik-75@mail.ru

Третинникова Татьяна Николаевна - зоолог II категории МАУ «Красноярский парк фрлоры и фауны «Роев ручей», г. Красноярск.

E-mail: tretinnikovatanya@mail.ru

Цель исследования - изучение адаптации диких животных к условиям содержания в зоопарке. Основные задачи исследования - сравнение поведенческих особенностей бельх медведей в дикой природе и зоопарке, адаптация бельх медведей к условиям зоопарка в зависимости от возрастной группы, влияние обогащения среды на поведение животных. Исследование проводилось в МАУ «Красноярский парк фолоры и фрауны «Роев ручей» в период с июня 2006 г. по ноябрь 2019 г. Объект исследования - белье медведи, рожденные в естественных условиях и поступившие в зоопарк в различных возрастах. Метод изучения - фоновые наблюдения для оценки состояния животных и круглосуточное наблюдение за их поведением, ведение журналов наблюдений по тренингу и обогащению среды. Проведен сравнительный анализ с литературными данными по бельм медведям, проживающим в естественных условиях. Климатические изме-
Nekipelova Elena Olegovna - Staff Scientist, MAI "Krasnjyarsk flora and fauna park "Royev rouchey", Krasnoyarsk.

E-mail: nekipelova73@mail.ru

Buyanov Ivan Yuryevich - Cand. Agr. Sci., Senior Staff Scientist, MAI "Krasnjyarsk flora and fauna park "Royev rouchey", Krasnoyarsk.

E-mail: ivyan@mail.ru

Shushakova Margarita Mikhaylovna - Head, Department of Mammals, MAl "Krasnjyarsk flora and fauna park "Royev rouchey", Krasnoyarsk.

E-mail: ritik-75@mail.ru

Tretinnikova Tatyana Nikolaevna - Zoologist of II Category, MAI "Krasnjyarsk flora and fauna park "Royev rouchey", Krasnoyarsk.

E-mail: tretinnikovatanya@mail.ru

нения способствовали социализации белых медведей. Особи, поступившие до 1 года и не вовлеченные в конфрликтные ситуации с человеком, быстрее адаптировались к условиям проживания в зоопарке. Обогащение среды является важным процессом при содержании животных в зоопарках. Со временем обогащение среды оказывает положительное влияние на животных. Особи, находящиеся в зоопарке дольше по времени (Феликс и Аврора), значительно меньше уделяли времени игрушкам, чем молодая самка Урсула. Среднее время занятости Урсулы составило - мячом 5,6 часа, цилиндром - 5,4 часа. Это связано с тем, что Урсула содержится отдельно, Феликс и Аврора - совместно, взаимодействуя друг с другом (социальное обогащение среды).

Ключевые слова: белье медведи, поведенческие особенности, адаптация, обогащение среды. 
The purpose of the work was to study the adaptation of wild animals to the conditions of their keeping in the zoo. The main tasks were comparing behavioral characteristics of polar bears in the wild and in the zoo, adapting polar bears to the conditions of the zoo depending on the age group, and the effect of enrichment on the behavior of animals. The studies were conducted in the city of Krasnoyarsk in the MAI "Krasnjyarsk flora and fauna park "Royev rouchey" from June 2006 to November 2019. The objects of the study were polar bears born in natural conditions and appeared in the zoo at various ages. The method of studying background observations was to assess the condition of animals and round-the-clock monitoring of their behavior, maintaining observation logs for training and enrichment of the environment. $A$ comparative analysis was carried out with published data on polar bears living in natural conditions. Climate change contributed to the socialization of polar bears. The individuals who arrived before 1 year of age and were not involved in conflict situations with the man quickly adapted to zoo living conditions. The enrichment of the environment is an important process in keeping animals in zoos. Over time, the enrichment has a positive effect on animals. The individuals kept in the zoo for more time (Felix and Aurora) gave to time to toys and a young female Ursula - much less. Average time of Ursula's playing made: with a ball 5.6 hours, a cylinder - 5.4 hours. It is connected with the fact that Ursula is kept separately, Felix and Aurora together, interacting with each other (social enrichment of the environment).

Keywords: polar bears, behavioral features, adaptation, environment enrichment.

Введение. Белый медведь, несмотря на интенсивные работы по мечению, повторные отловы и спутниковое слежение, до сих пор малоизучен в плане поведенческой экологии $[4,5]$. Первые белые медведи появились в Московском зоопарке в 1871 г., затем в Ленинградском и Новосибирском зоопарках в 1930-х гт. За период 1930-2015 гг. в Ленинградском зоопарке было рождено более 100 медвежат [3]. В Красноярском парке «Роев ручей» белые медведи содержатся с 2004 г.

Содержащиеся в неволе белые медведи по сравнению с бурыми кажутся менее сообрази- тельными и не столь ловкими. Белым медведям присуща некоторая «прямолинейность» в действиях, обусловленная однообразным образом жизни зверя, его узкой пищевой специализацией, отсутствием в природе врагов и конкурентов. Но достаточно даже недолгое время понаблюдать за белым медведем в естественной обстановке, чтобы убедиться в высоком уровне его психики. Белые медведи способны быстро оценивать условия природной среды и приспосабливаться к ним, в зависимости от них гибко менять тактику охоты $[7,8]$.

Цель исследования: изучение адаптации диких животных к условиям содержания в зоопарке.

Основные задачи исследования: сравнение поведенческих особенностей белых медведей в дикой природе и зоопарке, изучение адаптации белых медведей к условиям зоопарка в зависимости от возрастной группы, влияния обогащения среды на поведение животных.

Материалы и методы исследования. Материал собирался в городе Красноярске в МАУ «Красноярский парк флоры и фауны «Роев ручей» с июня 2006 г. по ноябрь 2019 г. Объект исследования - белые медведи, рожденные в естественных условиях и поступившие в парк в разных возрастах. Все животные содержатся в одинаковых условиях. За медведями ведутся фоновые наблюдения для оценки состояния животных и круглосуточное видеонаблюдение за их поведением. Также ведутся журналы наблюдений по тренингу и обогащению среды. Проведен сравнительный анализ полученных данных с литературными данными по медведям, проживающим в естественных условиях.

Результаты исследования и их обсуждение. В естественных условиях основная социальная единица популяции белых медведей представлена самкой с детенышами, в остальных случаях белые медведи ведут одиночный образ жизни. В тех районах, где медведи находятся на берегу в течение лета, можно наблюдать группы взрослых самцов и даже увидеть участие таких животных в социальных играх [9]. Климатические изменения в Арктике, сопровождающиеся сокращением ледового покрова арктических морей в летний период, привели к значительному сниже- 
нию площадей местообитаний, пригодных для белого медведя, прежде всего в Баренцевом и Чукотском морях. Данные изменения способствовали социализации белых медведей [3].

Этот вывод подтверждается как нашими наблюдениями, так и опытом других зоопарков $[1,9]$. На протяжении 8 лет в парке содержались две разнополые молодые особи в соседних вольерах и были соединены как пара для размножения. В течение 2 лет совместного содержания не наблюдалось проявления агрессии по отношению к делению территории, но со стороны Феликса изредка наблюдалась агрессия по отношению к еде.

В природе белые медведи хорошо плавают и ныряют за едой. Поднявшись с едой, звери могут ложиться на спину, как каланы, и есть добычу. Самки с детенышами до года избегают плавания на длинные дистанции. Если плавание неизбежно, самки переносят детенышей на спине. При подготовке ко сну медведи роют яму в снегу либо в песке, гальке. При охоте белые медведи могут долго стоять неподвижно, затем резко бросаться вниз, чтобы проломить лед для добычи кольчатой нерпы. При поимке добычи молодые медведи играют с пищей, подбрасывая ее в воздух, и бросают в воду, ныряя за ней и доставая обратно [9].

Поведенческие особенности у детенышей, обучавшихся матерью, сохраняются на протяжении всей жизни, даже в условиях зоопарка (табл. 1).

Выяснено, что к искусственным условиям проще и быстрее привыкают звери, поступившие в зоопарк в возрасте до 6 месяцев включительно.

Особи от 7 месяцев адаптируются сложнее, дольше. В Парке «Роев ручей» содержатся четыре белых медведя, спасенных из природы.

Самец по кличке Феликс самостоятельно вышел на метеостанцию в возрасте 6 месяцев, самка по кличке Аврора была выведена раненой медведицей к метеостанции в возрасте 4 месяцев. Самка по кличке Марфа (возраст 1,5 года) разгуливала по г. Норильску без агрессивных проявлений поведения и боязни транспорта (рис.).

Появление природного поведения у белых медведей в парке «Роев ручей»

\begin{tabular}{|l|c|c|c|c|}
\hline \multicolumn{1}{|c|}{ Вид поведения } & Урсула & Марфра & Феликс & Аврора \\
\hline Плавание & + & + & $-/$ & + \\
\hline Ныряние & + & + & $-/+$ & + \\
\hline «Калан» & + & - & - & + \\
\hline «Пролом льда» & + & + & - & - \\
\hline Скрадывание добычи & + & - & - & - \\
\hline «Замирание» & + & + & - & + \\
\hline Подготовка ко сну («рытье ямы») & + & + & + & + \\
\hline Игра с едой & + & - & - & + \\
\hline
\end{tabular}

Примечание: (+) - положительная реакция; (-) - отрицательная реакция; (+/-) - неохотно. 


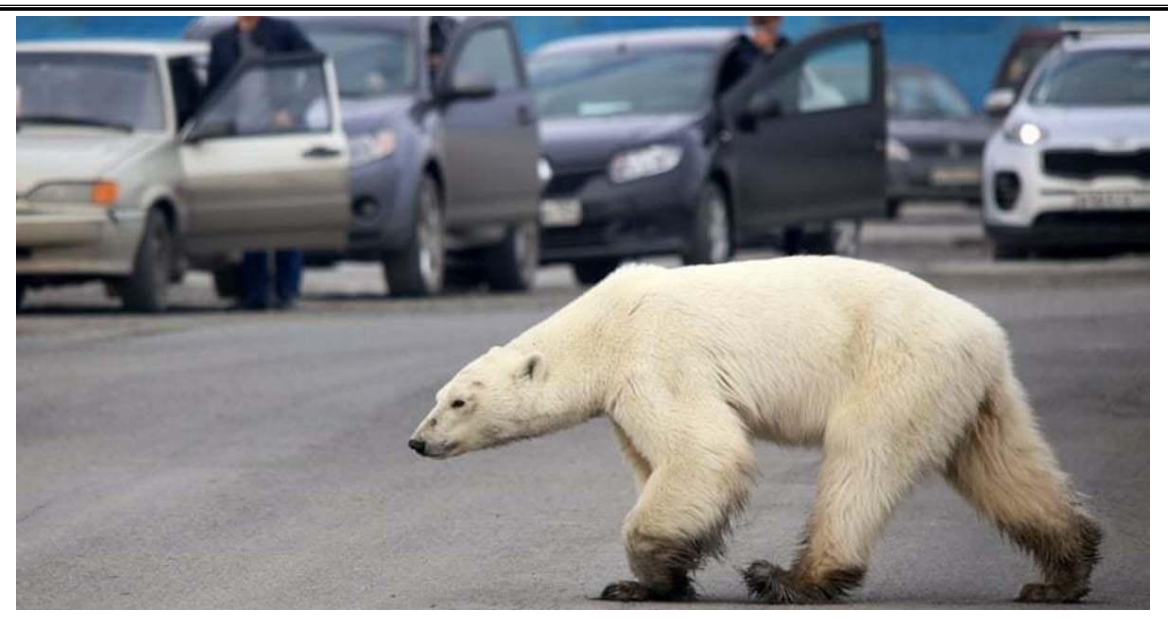

Белая медведица Марфа (е. Норильск)

Самка по кличке Урсула (возраст 11 месяцев) обитала возле городского поселения Дик$\mathrm{coH} \mathrm{в} \mathrm{течение} \mathrm{двух} \mathrm{месяцев.} \mathrm{Все} \mathrm{мероприятия}$ по отпугиванию животного не принесли ожидаемых результатов. Медведица возвращалась в поселок, питалась на свалках, бывали случаи, когда она ночевала под домами.
Особи, поступившие в парк без конфоликтной ситуации с человеком, из-за которой они были изъяты из дикой природы, более спокойно себя ведут и быстрее адаптируются к искусственным условиям (табл. 2).

\section{Реакция белых медведей на раздражитель}

\begin{tabular}{|l|c|c|c|c|}
\hline \multirow{2}{*}{ Белые медведи } & \multicolumn{4}{|c|}{ Раздражитель } \\
\cline { 2 - 5 } & Автотранспорт & Резкий звук & $\begin{array}{r}\text { Закрытое } \\
\text { помещение } \\
\text { (перегонка) }\end{array}$ & Посетители \\
\hline Феликс & + & - & - & - \\
\hline Аврора & - & - & - & - \\
\hline Урсула & + & + & - & - \\
\hline Марфра & $+/-$ & - & - & - \\
\hline
\end{tabular}

Примечание: (+) реагирует на раздражитель; (-) - не реагирует на раздражитель.

Наиболее заметная реакция на раздражители у белой медведицы по кличке Урсула. Причина - конфликтная ситуация с человеком в природе. Ее два месяца отгоняли от населенного пункта при помощи транспорта и резких звуков. На остальные раздражители она реагирует адекватно. Самец по кличке Феликс проявляет раздражение на автотранспорт из-за испуга в молодом возрасте.

Обогащение среды как способ повышения благополучия животных, живущих в зоопарке, получило широкое распространение в последние тридцать лет [2]. Классификация оценки вовлеченности животного в программу обогащения среды разработана в 2001 г. [6].

Занятость медведей игрушками дана в таблице 3. Из представленных данных видно, что особи, находящиеся в зоопарке дольше по времени, Феликс и Аврора значительно меньше уделяли времени игрушкам, чем молодая самка Урсула. Среднее время занятости Урсулы составило: мячом - 5,6 ч; цилиндром - 5,4 ч. Это связано с тем, что Урсула содержится отдельно, Феликс и Аврора - совместно, взаимодействуя друг с другом (социальное обогащение среды). 


\section{Занятость белых медведей игрушками с разным наполнением}

\begin{tabular}{|c|c|c|c|c|c|c|}
\hline \multirow{2}{*}{ Обогащение среды } & \multicolumn{2}{|c|}{ Самец Феликс (возраст 14 лет) } & \multicolumn{2}{|c|}{ Самка Аврора (возраст 9 лет) } & \multicolumn{2}{|c|}{ Самка Урсула (возраст 1,5 года) } \\
\hline & $\begin{array}{c}\text { Интерес, } \\
\text { время/балл }\end{array}$ & $\begin{array}{c}\text { Потеря интереса, } \\
\text { время/балл }\end{array}$ & $\begin{array}{c}\text { Интерес, } \\
\text { время/балл }\end{array}$ & $\begin{array}{c}\text { Потеря интереса, } \\
\text { время/балл }\end{array}$ & $\begin{array}{c}\text { Интерес, } \\
\text { время/балл }\end{array}$ & $\begin{array}{c}\text { Потеря интереса, } \\
\text { время/балл }\end{array}$ \\
\hline \multicolumn{7}{|c|}{ Сборно-разборный шар } \\
\hline Предметное & 2 мин/4 & 2 мин/4 & 2 мин/4 & 2 мин/4 & 35 мин/5 & $14 / 5$ \\
\hline Запаховое & 20 мин/5 & $24 / 5$ & 25 мин/5 & 30 мин/5 & 1 ч 20 мин/5 & $64 / 5$ \\
\hline Кормовое & 33 мин/5 & $14 / 5$ & 35 мин/5 & 50 мин/5 & $24 / 5$ & $124 / 5$ \\
\hline Кормовое + запаховое & $23 м и н / 5$ & 2 ч 10 мин/5 & 30 мин/5 & 35 мин/5 & 37 мин/5 & $94 / 5$ \\
\hline \multicolumn{7}{|c|}{ Сборно-разборный цилиндр } \\
\hline Предметное & 2 мин/4 & 5 мин/4 & 34 мин/5 & $44 / 5$ & 37 мин/5 & $64 / 5$ \\
\hline Запаховое & 22 мин/5 & $54 / 5$ & 17 мин/4 & 3 ч 30 мин/5 & 45 мин/5 & $74 / 5$ \\
\hline Кормовое & 15 мин/4 & $44 / 5$ & 10 мин/4 & $64 / 5$ & 44 мин/5 & $84 / 5$ \\
\hline Кормовое + запаховое & 32 мин/5 & $84 / 5$ & 26 мин/5 & 4 ч 30 мин/5 & 53 мин $/ 5$ & $64 / 5$ \\
\hline
\end{tabular}




\section{Выводы}

1. Выявлено, что полученные медвежатами от матери навыки в естественной природе сохраняются и в условиях содержания в зоопарке. Количество и качество полученных навыков зависит от времени, проведенного с медведицей.

2. В зависимости от возрастной группы, в которой особь была доставлена в зоопарк, зависит время, затрачиваемое на адаптацию к искусственным условиям содержания. Особи, поступившие в младшевозрастной группе до 6 месяцев, адаптируются быстрее, чем особи, поступившие в старшем возрасте.

3. Влияние обогащения среды на белых медведей усиливается с увеличением времени проживания в условиях содержания в зоопарке.

\section{Литература}

1. Баловацкая С.А. Некоторые особенности медведей Большереченского зоопарка // Екатеринбургский зоопарк: научные исследования в зоологических парках. - Екатеринбург, 2006. - 97 с.

2. Буянов И.Ю., Шушакова М.М., Модин А.В., Третинникова Т.Н. и др. Мониторинг реакции семейства кошачьи на обогащение среды их обитания в парке «Роев ручей». Брянск, 2019. - 7 с.

3. Гергилевич Н.М. Знакомьтесь: Ленинградский зоопарк / Зоопарк Ленинградский. СПб., 2015. - 44 с.

4. Забота о диких животных: стратегия Всемирной ассоциации зоопарков и аквариумов в сфрере благополучия животных / пер. А.В. Симонова; ред. Г.В. Вахрушева, Ю.Д. Журавлев; Евроазиатская ассоциация зоопарков и аквариумов (ЕАРАЗА), Московский зоопарк. - М.: КолорВитрум, 2015. $88 \mathrm{c}$.

5. Овсяников Н.Г. Поведенческие механизмы внутрипопуляционных процессов хищных млекопитающих Арктики: автореф. дис. ... д-ра биол. наук. - М., 2012. - 49 с.

6. Подтуркин А.А. Обзор практики обогащения среды: методы подбора способов обогащения среды и оценка их результативности в условиях зоопарка / Московский 300парк. - М., 2015. - 200 c.
7. Успенский С.М. Белый медведь. - М.: Наука, 1977. - 80 с.

8. Стирлинг Ян. Белые медведи: естественная история исчезающего вида: пер. с англ. Казань, 2016. - 336 с.

9. AZA Bear TAG 2009. Polar Bear (Ursus maritimus) Care Manual. Association of Zoos and Aquariums, Silver Spring, MD.

\section{Literatura}

1. Balovackaya S.A. Nekotorye osobennosti medvedej Bol'sherechenskogo zooparka I Ekaterinburgskij zoopark: nauchnye issledovaniya $\mathrm{V}$ zoologicheskih parkah. Ekaterinburg, 2006. - $97 \mathrm{~s}$.

2. Buyanov I.Yu., Shushakova M.M., Modin A.V., Tretinnikova T.N. i dr. Monitoring reakcii semejstva koshach'i na obogashchenie sredy ih obitaniya v parke «Roev ruchej». - Bryansk, 2019. - $7 \mathrm{~s}$.

3. Gergilevich N.M. Znakom'tes': Leningradskij zoopark / Zoopark Leningradskij. - SPb., 2015. - $44 \mathrm{~s}$.

4. Zabota o dikih zhivotnyh: strategiya Vsemirnoj associacii zooparkov i akvariumov $v$ sfere blagopoluchiya zhivotnyh I per. A.V. Simonova; red. G.V. Vahrusheva, Yu.D. Zhuravlev; Evroaziatskaya associaciya zooparkov i akvariumov (EARAZA), Moskovskij zoopark. - M.: KolorVitrum, 2015. - $88 \mathrm{~s}$.

5. Ovsyanikov N.G. Povedencheskie mekhanizmy vnutripopulyacionnyh processov hishchnyh mlekopitayushchih Arktiki: avtoref. dis. ... d-ra biol. nauk. - M., 2012. - 49 s.

6. Podturkin A.A. Obzor praktiki obogashcheniya sredy: metody podbora sposobov obogashcheniya sredy i ocenka in rezul'tativnosti v usloviyah zooparka I Moskovskij zoopark. - M., 2015. - $200 \mathrm{~s}$.

7. Uspenskij S.M. Belyj medved'. - M.: Nauka, 1977. - 80 s.

8. Stirling Yan. Belye medvedi: estestvennaya istoriya ischezayushchego vida: per. s angl. Kazan', 2016. - $336 \mathrm{~s}$.

9. AZA Bear TAG 2009. Polar Bear (Ursus maritimus) Care Manual. Association of Zoos and Aquariums, Silver Spring, MD. 